Leonid Bannikov, Anna Smirnova and Serhiy Nesterenko

\title{
INTERPRETATION OF SALTS INFLUENCE ON THE REGEN ERATION PROCESS OF RICH THIOARSENATE SOLUTION BY OXIDATIVE REDUCTION POTENTIAL MEASUREMENT
}

\author{
Ukrainian State Research Institute of Carbochemistry \\ 7 Vesnina St., 61023 Kharkiv, Ukraine; ukhinbannikov@gmail.com
}

Received: December 04, 2014 / Revised: April 06, 2015 / Accepted: August 12, 2015

(C) Bannikov L., Smirnova A., Nesterenko S., 2016

\begin{abstract}
In the article various contaminates of thioarsenate process of coke oven gas desulfurization were investigated by measuring oxidative-reduction potential (ORP). ORP measuring is a simple and indicative method of activity determination. The article has also explained the thiosulfate influence on the activity of scrubbing solution based on $\mathrm{As}^{3+} / \mathrm{As}^{5+}$ chemistry.
\end{abstract}

Keywords: thioarsenate process, activity, contaminating effect.

\section{Introduction}

Despite the decrease in $\mathrm{H}_{2} \mathrm{~S}$ yield under coking process from coal blends in Ukrainian enterprises [1-3], coke oven gas purification is under strict attention of national legislation.

Liquid oxidation methods of coke oven gas desulfurization are used for thorough purification of hydrogen sulfide and organic sulfur compounds $[4,5]$. As opposed to absorption/desorption methods in the liquid oxidation solution the chemical reaction of hydrogen sulfide oxidation takes place. As the result the concentration of hydrogen sulfide in the lean solution decreases and causes the higher degree of gas purification.

Thioarsenate process was developed in $20-30^{\text {th }}$ years of the last century for purification of industrial gases from hydrogen sulfide and is still used at three Ukrainian coke plants. Process is noticeable by the reagents low consumption and low cost catalyst (arsenic trioxide) and that is why it has some advantages over the widespread oxidation methods based on vanadium, quinone, ironchelating and similar catalyst complexes [6].
In the process of coke oven gas purification an absorption of hydrogen sulfide by thioarsenate solution takes place $[7,9]$ :

$$
\mathrm{H}_{2} \mathrm{~S}+\mathrm{OH}^{-} \rightarrow \mathrm{HS}^{-}+\mathrm{H}_{2} \mathrm{O}
$$

followed by $\mathrm{H}_{2} \mathrm{~S}$ oxidation:

$$
\mathrm{HS}^{-}+\mathrm{AsS}_{m} \mathrm{O}^{3-}{ }_{4-m} \rightarrow \mathrm{AsS}_{m} \mathrm{O}_{3-m}^{3-}+\mathrm{S}+\mathrm{OH}^{-}
$$

and regeneration of arsenic complex by air blowing:

where $m=1-3$.

$$
\mathrm{AsS}_{m} \mathrm{O}_{3-m}^{3-}+1 / 2 \mathrm{O}_{2} \rightarrow \mathrm{AsS}_{m} \mathrm{O}_{4-m}^{3-}
$$

In fact this reaction mechanism is not exclusive interpretation, the literature sources often refer to the Gollmar's mechanism based on the conversion of active oxygenated thioarsenate salts with a high sulfur content into "oxygen" inactive oxygenated arsenate salts. Gollmar $\mathrm{H}_{2} \mathrm{~S}$ absorption step is represented by Eq. (4) [6]:

$$
\mathrm{Na}_{4} \mathrm{As}_{2} \mathrm{O}_{2} \mathrm{~S}_{5}+\mathrm{H}_{2} \mathrm{~S}=\mathrm{Na}_{4} \mathrm{As}_{2} \mathrm{~S}_{6} \mathrm{O}+\mathrm{H}_{2} \mathrm{O}
$$

and the regeneration step is represented by:

$$
\mathrm{Na}_{4} \mathrm{As}_{2} \mathrm{~S}_{6} \mathrm{O}+0.5 \mathrm{O}_{2}=\mathrm{Na}_{4} \mathrm{As}_{2} \mathrm{~S}_{5} \mathrm{O}_{2}+\mathrm{S}
$$

The Gollmar's reaction mechanism differs from modern interpretations of the chemistry of liquid oxidation processes [7,9], predominantly because it does not change the oxidation state of arsenic as the main catalyst complex.

From operating experience the thioarsenate process found that purification efficiency is reduced as a result of solution contamination from the coke oven gas and especially with the wash oil from the benzene recovery unit as the predecessor gas treatment unit. Also sour coke oven gas contains naphthalene, phenol, pyridine, hydrocarbons, dust and tars.

Contaminations from coke oven gas can cause severe problems when used in the oxidative desulfurization process. Some of them cause undesirable foaming when gas is in contact with the solution; the 
organic sulfur-containing components are subjected to partial oxidation, and are emitted into atmosphere during the regeneration process. Phenols and polycyclic aromatic compounds can change the color of recovered elemental sulfur. The content of benzene hydrocarbons in the sour coke oven gas must not exceed $5 \mathrm{~g} / \mathrm{m}^{3}$, otherwise emulsion may be formed in the regenerator, which prevents sulfur flotation process [6]. Organic substances can also reduce the rate of regeneration of the rich solution and decrease the air requirements from 4-5 to $7-10 \mathrm{~m}^{3} / \mathrm{kg} \mathrm{H}_{2} \mathrm{~S}$ [14].

To eliminate the negative influence of impurities the thioarsenate desulfurization units are installed after ammonia and benzene recovery units. For reducing the tar and wash oil content electrostatic precipitators are installed before thioarsenate units and lean absorptive solution is heated to $313-315 \mathrm{~K}$ for avoiding condensation of tar components and naphthalene. Pre-treatment of the coke oven gas in the Venturi scrubber or in a coalescing filter is also possible. It should be noted that entering the regenerator the air contains compressor oils which can also cause degradation of the process solution.

Besides deterioration of the solution absorptive properties resulted from impurity contamination the catalyst is consumed with the spent solution, recovered sulfur and purified gas. While lowering the $\mathrm{pH}$ solution less than 7.6 the oxygenated thioarsenate compounds decompose with the formation of sparingly soluble sulfuric compounds of arsenic, which form deposits on the equipment surface. It causes decrease in concentration of arsenic compounds in the working solution and, finally, reduces the efficiency of hydrogen sulfide purification from coke oven gas.

To control the quality of the working solution and its capacity for effective gas purification from hydrogen sulfide the activity index is used. Activity index of the working solution reflects the ability of the solution to absorb hydrogen sulfide from coke oven gas and the regeneration degree of rich solution. Apparent activity index of absorbent is most commonly used, and is determined by the formula:

$$
\mathrm{A}_{\text {app }}=\frac{\mathrm{As}_{2} \mathrm{O}_{3}{ }^{1}-\mathrm{As}_{2} \mathrm{O}_{3}{ }^{2}}{\mathrm{As}_{2} \mathrm{O}_{3}{ }^{3}} \cdot 100
$$

where $\mathrm{As}_{2} \mathrm{O}_{3}{ }^{1}$ - "residual" arsenic - stable under acid titration arsenic and arsenious salts as well as relatively stable salt of oxygenated thioarsenic acids with low sulfur content; $\mathrm{As}_{2} \mathrm{O}_{3}{ }^{2}$ - "oxygenated" arsenic - precipitated salts after magnesia mixture treatment; $\mathrm{As}_{2} \mathrm{O}_{3}{ }^{3}$-"total" arsenic - total content of arsenic in the solution. All types of arsenic compounds are expressed in terms of $\mathrm{As}_{2} \mathrm{O}_{3}$.

Moreover, the activity can be evaluated by the difference of $\mathrm{pH}$ between rich and lean solutions, by weight of hydrogen sulfide absorbed by lean solution (g $\mathrm{H}_{2} \mathrm{~S} / \mathrm{cm}^{3}$ solution) or by the volume of oxygen absorbed by lean solution $\left(\mathrm{cm}^{3} \mathrm{O}_{2} / 20 \mathrm{~cm}^{3}\right.$ solution). The oxygen concentration in the exhaust air after the regenerator is the efficiency index both of the air distribution in the regenerators and activity of the working solution.

L. Grumberg et al. [8] evaluated the contamination effect on apparent activity of the absorption solution while adding wash oil, sodium phenolate, phenol, benzene, pyridine bases and air compressor oils to a solution. The organic impurities decrease the absorption solution activity approximately by $1.2-1.4$ times. To evaluate the influence of specific impurities on the process it is necessary to carry out a series of labor-intensive processes for distinctive analysis of "total" arsenic (by oxidation all various forms of arsenic to a pentavalent form), of "residual" arsenic (by acidification, followed by precipitation of arsenic sulfuric compounds and analytical determination of arsenic in the filtrate) and of "oxygenated" arsenic (by $\mathrm{As}^{5+}$ precipitation with magnesia mixture followed by nitric acid dissolving).

V. Nizhegorodtsev et al. [9] evaluated negative effect of impurities (semi-coking tars, volatile phenols, pyridine bases, autoclave liquid) by determining $\mathrm{As}^{5+}$ content. Above mentioned contaminants decrease $\mathrm{As}^{5+}$ content after regeneration process except of phenols. S. Goland et al. [14] confirmed that phenol enhances the regeneration reaction and promotes sulfur substitution by oxygen in oxygenated thioarsenate salts to form the final product - dibasic sodium thioarsenate. Thus, the effect of interfering impurities depending on their type can be attributed to incomplete or excess regeneration process.

As a result of excess regeneration process, particularly when the temperature rises to $313-333 \mathrm{~K}$ and at $\mathrm{pH}>8$, as well as at high oxygen concentration in the solution the rate of thiosulfates formation increases. The concentration of dissolved oxygen in the solution in some liquid phase oxidation process for $\mathrm{H}_{2} \mathrm{~S}$ removal is estimated by measuring the value of the redox potential (ORP) [6].

Electrode in ORP-meter gains the potential at immersion in the solution where reversible redox systems are located. Rate of installation velocity is often very slow and depends on several factors, foremost among which is the redox capacity of the medium, that is, the concentration of oxidized and reduced forms in the solution. It is known that the time reading of the millivoltmeter when measuring ORP in the negative range can vary from 1-2 to $30 \mathrm{~min}$. For thioarsenate solutions the time of potential reading was far higher.

At technological regime failure and decrease in the activity of the absorption solution it is necessary to identify quickly and eliminate the source of contamination from the coke oven gas, compressed air or autoclave liquid that is recycled from the sulfur melting stage. As already noted, the coke oven gas brought different impurities which may be reduced by normalization of 
technological processes of several units arranged before desulfurization plant.

The task of research is to determine thiosulfate and thiocyanate influence on activity of scrubbing solution when total salt content of the solution (thiosulfate and thiocyanate) is increased. Such a problem cannot be solved by estimating "apparent" activity of the solution. It is known that increasing the salinity of the solution in an "absorption-desorption" desulfurization process has negative effects on the $\mathrm{H}_{2} \mathrm{~S}$ absorption efficiency [12], because of the ion mobility decreasing. Moreover, increase in the solution concentration of thioarsenate process reduces the solubility of oxygen, increases the tendency of the solution to crystallize in a dead space of apparatus, leads to the scrubber nozzle clogging, causes an increase in the density, viscosity of the solution and the operating cost for solution pumping [15]. Nevertheless, thioarsenate unit staff associates thiosulfate concentration with the total content of arsenic in the solution.

\section{Experimental}

To solve this problem, we used the method of measuring the oxidation redox potential under regeneration of the solution sample, including the introduction of various interfering impurities $[10,11]$. The ORP shows activity (or force) of oxidizing and reducing agents in accordance with their nature and concentrations. Often the ORP measurements are used for monitoring the fullness of redox reaction. When the reaction is close to completion, there is an inflection point which can be determined from the ORP curves. It is hard to predict the absolute value and character of the curve because at the same time there is a variety of redox pairs in the thioarsenate solution that may have the significant effect on the ORP curve.

The multi-parameter device Ulab MP551 ( $\mathrm{pH}$ /oximeter/ORP/conductometer) with the electronconducting glass electrode EO-01 was used for the measurements. It is known that prolonged contact with hydrogen sulfide deteriorates the platinum electrode at negative values. The EO-01 electrode has the less current

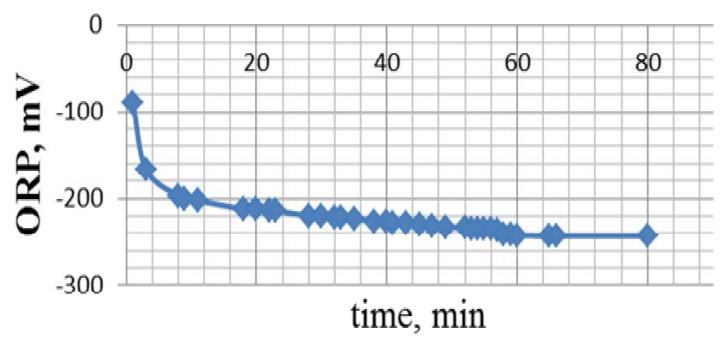

Fig. 1. ORP measurement curve of rich solution exchange than the platinum wire in most solutions of reversible redox systems. Using EO-01 electrode gives the possibility to determine the concentrations in reversible systems, but the time which we gain from the equilibrium potentials is longer. It is important to note that for EO-01 electrode the catalysis effect and the influence of gaseous oxygen and hydrogen are not typical.

Method of determining the influence of interfering organic additives on the absorption solution with ORP potential has been developed in [10]. The working rich solution contaminants had been injected to the flask with rich solution, then the regeneration process was carried out by blowing air through the solution. At certain time intervals values of ORP potential were measured. The experiments were conducted with the following parameters: the volume of the rich solution $-25 \mathrm{~cm}^{3}$, air flow $-2 \mathrm{dm}^{3} / \mathrm{min}$, the temperature is $289-297 \mathrm{~K}$, $\mathrm{Na}_{2} \mathrm{~S}_{2} \mathrm{O}_{3}-250 \mathrm{~g} / \mathrm{dm}^{3}, \mathrm{NaSCN}-190 \mathrm{~g} / \mathrm{dm}^{3}$.

According to the way of ORP gaining the measurements were performed in such a way: first ORP of rich solution had been read (time of ORP steady reading 50-75 $\mathrm{min}$ ), then the air micro-compressor was connected, that resulted in ORP increasing at oxidation. The following additives were used: sodium thiosulfate pentahydrate (brand "chemically pure"), sodium thiocyanate (brand "chemically pure").

Since ORP potential is an expression of oxidationredox ability of the substances, the aeration of rich solution results in a potential jump to the more positive values indicating the excess of oxidant in the solution. The introduction of impurities into a rich solution can alter the capacity of the regenerated one, which is characterized by the direction and degree of the impurities effect on the oxidation process.

For working rich solution without additives the time of ORP steady reading $(-245 \mathrm{mV})$ was about $80 \mathrm{~min}$ (Fig. 1). Since millivoltmeter readings have not stabilized for $30 \mathrm{~min}$, the final value was determined by the asymptote of the curve stabilization potential. With three parallel measurements ORP potential of rich solution ranged from -245 to $-252 \mathrm{mV}$ (Table 1 ).

Time of ORP steady reading $(-176 \mathrm{mV})$ under air blowing was about $20 \mathrm{~min}$ (Fig. 2).

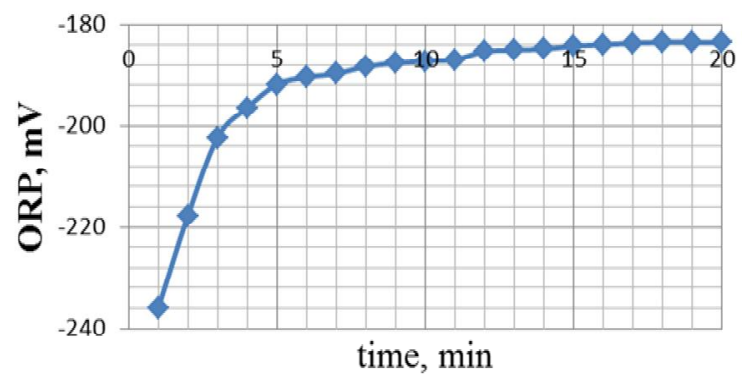

Fig. 2. ORP measurement curve of rich solution under aeration 
ORP potentials of rich solution

\begin{tabular}{|l|c|c|c|}
\hline & $\begin{array}{c}\text { Number of } \\
\text { measurement }\end{array}$ & ORP, $\mathrm{mV}$ & Time of ORP steady reading, min \\
\hline \multirow{2}{*}{$\begin{array}{l}\text { Working rich solution, II unit, PJSC } \\
\text { "ZAPOROZHCOKE" }\end{array}$} & 1 & -245.0 & 51 \\
\cline { 2 - 4 } & 2 & -245.1 & 67 \\
\hline
\end{tabular}

Table2

An effect of salt content on ORP value at air blowing process

\begin{tabular}{|c|c|c|c|c|c|c|}
\hline \multirow[b]{2}{*}{ Solution sample } & \multicolumn{3}{|c|}{ Thiosulfate ions adding } & \multicolumn{3}{|c|}{ Thiocyanate ions adding } \\
\hline & $\begin{array}{c}\text { Value of } \\
\text { potential, } \mathrm{mV}\end{array}$ & $\begin{array}{l}\text { Time of ORP } \\
\text { steady reading, } \\
\text { min }\end{array}$ & $\mathrm{pH}$ & $\begin{array}{c}\text { Value of } \\
\text { potential, } \mathrm{mV}\end{array}$ & $\begin{array}{l}\text { Time of ORP } \\
\text { steady reading, } \\
\text { min }\end{array}$ & $\mathrm{pH}$ \\
\hline $\begin{array}{l}\text { Working rich } \\
\text { solution }\end{array}$ & -245.1 & 67 & 7.99 & -245.1 & & 7.99 \\
\hline $\begin{array}{l}\text { Oxidized working } \\
\text { rich solution }\end{array}$ & -176.4 & 28 & 8.04 & -176.0 & 28 & 8.04 \\
\hline $\begin{array}{l}\text { The same with } \\
\text { adding of } 20 \mathrm{~g} / 1\end{array}$ & -177.0 & 29 & 7.94 & -170.4 & 24 & 8.04 \\
\hline $\begin{array}{l}\text { The same with } \\
\text { adding of } 35 \mathrm{~g} / 1\end{array}$ & -178.4 & 21 & 7.94 & -173.0 & 24 & \\
\hline $\begin{array}{l}\text { The same with } \\
\text { adding of } 50 \mathrm{~g} / 1\end{array}$ & -178.1 & 22 & 7.92 & -181.4 & 24 & 8.03 \\
\hline $\begin{array}{l}\text { The same with } \\
\text { adding of } 100 \mathrm{~g} / 1\end{array}$ & -175.4 & 25 & 7.96 & & & \\
\hline $\begin{array}{l}\text { Up to solution } \\
\text { saturation }\end{array}$ & -171.5 & 22 & 7.95 & -181.2 & 12 & \\
\hline
\end{tabular}

\section{Results and Discussion}

The results of determination the effect of thiosulfate additives during rich solution regeneration are presented in Table 2. The last experiment was conducted under oversaturated solution and air blowing was carried out under the presence of insoluble salt precipitate.

Increase in the concentration of salts formed by strong acids and a strong base (thiosulfate and thiocyanate) does not result in $\mathrm{pH}$ change, therefore under the usual $\mathrm{As}^{3+}$ oxidation (Eq. (9)) hydrogen ion concentration does not affect the ORP potential according to the Nernst equation:

$$
\mathrm{E}_{\frac{\mathrm{AsO}_{4}{ }^{3-}}{\mathrm{AsO}_{3}^{3-}}}=\mathrm{E}^{0}+\frac{0.059}{2} \log \frac{\left[\mathrm{AsO}_{4}^{3-}\right] \cdot\left[\mathrm{H}^{+}\right]^{2}}{\left[\mathrm{AsO}_{3}{ }^{3-}\right]}
$$

where $E^{0}-$ standard redox potential of this pair; $\left[\mathrm{AsO}_{4}{ }^{3-}\right]$, $\left[\mathrm{H}^{+}\right],\left[\mathrm{AsO}_{3}{ }^{3}\right]$ - activity of the corresponding ions.

Increase in concentration of thiosulfate and thiocyanate rises the ionic strength of the solution, which lowers the activity coefficients of arsenite and arsenate ions. As ion charge is the same, so we can assume that a mutual compensation of ion activities take place. As the potential is affected by the logarithm of the activity, the significance of the activity coefficients further reduces. In addition, the concentration of hydrogen ions is in the second degree, and its impact on the value of ORP is more than the influence of arsenite and arsenate concentrations.

Lowering the oxygen solubility as a result of growth of the total salt content in the investigated range of concentrations had no effect on the measured ORP value.

Under experimental conditions, excessive increase of thiosulfate and thiocyanate in the working solution until complete saturation caused deviations in the value of ORP potential $\pm 5 \mathrm{mV}$, which was within the measurement error. According to the studies on the effect of salinity on the sensitivity of the special electrodes for the voltametric determination of $\mathrm{As}(\mathrm{V})$ concentration in water, the content of neutral salts has also no effect on the $\operatorname{As}(\mathrm{V})$ concentration [16].

The question arises: why is the concentration of thiosulfate associated with the content of total arsenic in the solution and has an impact on the activity that has been found by the staff observations of thioarsenate unit? The nature of this association is illustrated in Fig. 3.

Thiosulfate determination is carried out by direct volumetric titration, based on the oxidation of thiosulfate ions by the reaction with an iodine solution:

$$
2 \mathrm{~S}_{2} \mathrm{O}_{3}{ }^{2-}+\mathrm{J}_{2} \rightarrow \mathrm{S}_{4} \mathrm{O}_{6}{ }^{2-}+2 \mathrm{~J}^{-}
$$




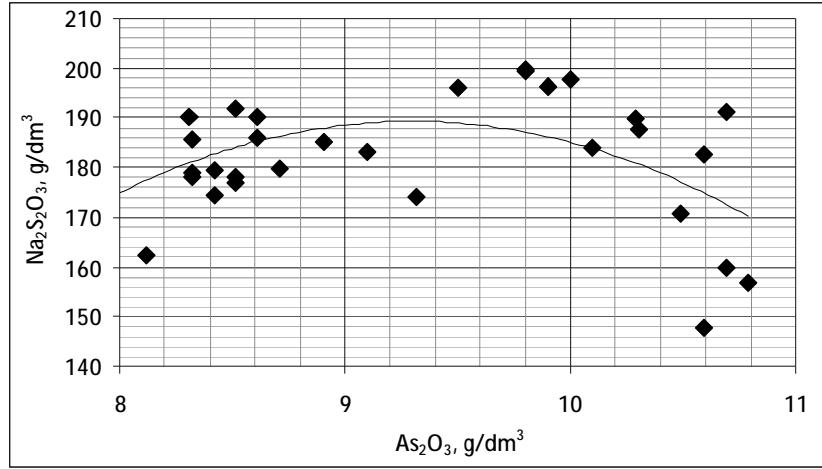

Fig. 3. Concentration of sodium thiosulfate $v s$. total arsenic content

According to Gollmar (Eqs. (4) and (5)) only pentavalent arsenic is present in the absorption solution. If the trivalent arsenic is present in the solution close to neutral, it also consumes iodine:

$$
\mathrm{AsO}_{3}{ }^{3-}+\mathrm{J}_{2}+\mathrm{H}_{2} \mathrm{O} \rightarrow \mathrm{AsO}_{4}{ }^{3-}+2 \mathrm{~J}^{-}+2 \mathrm{H}^{+}
$$

Thus, the concentration of thiosulfate which analytically has been determined in the solution is the total content of $\mathrm{As}(\mathrm{III})$ and $\mathrm{S}_{2} \mathrm{O}_{3}{ }^{2-}[9]$.

Therefore, in the left branch of the curve (Fig. 3), the growth of the concentration $\mathrm{S}_{2} \mathrm{O}_{3}{ }^{2-}$ is coupled with the increased concentration of trivalent arsenic in the solution. In the right branch of the curve the decreased concentrations of thiosulfate, as determined by the method described above, may be a consequence of decreased concentration of $\mathrm{As}(\mathrm{III})$ due to peroxidation into As(IV) at the aeration intensification.

Hencce, the conservative purification Gollmar mechanism that uses pentavalent oxy-thioarsenate, thioarsenate and oxygenated arsenic salts does not explain the influence of the As(III) content on the process.

It should be noted that the interpretation of the process by Eqs. (1)-(3) [7, 9] explains the excessive regeneration of the solution by increase in the $\mathrm{As}^{5+}$ content, and the process of incomplete regeneration by the absence of impurities influence (mostly organic). In our opinion, it would be logical to explain the incomplete regeneration by increased content of $\mathrm{As}^{3+}$, however, then the absorption reaction of hydrogen sulfide should proceed with $\mathrm{As}^{3+}$.

Then the mechanism of thioarsenate absorptionregeneration process is logically explained by reactions of Giammarco-Vetrocoke [6]:

absorption:

$$
\mathrm{KH}_{2} \mathrm{AsO}_{3}+3 \mathrm{H}_{2} \mathrm{~S}=\mathrm{KH}_{2} \mathrm{AsS}_{3}+3 \mathrm{H}_{2} \mathrm{O}
$$

digestion:

$\mathrm{KH}_{2} \mathrm{AsS}_{3}+3 \mathrm{KH}_{2} \mathrm{AsO}_{4}=3 \mathrm{KH}_{2} \mathrm{AsO}_{3} \mathrm{~S}+\mathrm{KH}_{2} \mathrm{AsO}_{3}$

acidification:

$$
\mathrm{KH}_{2} \mathrm{AsO}_{3} \mathrm{~S}=\mathrm{KH}_{2} \mathrm{AsO}_{3}+\mathrm{S}
$$

oxidation:

$$
2 \mathrm{KH}_{2} \mathrm{AsO}_{3}+\mathrm{O}_{2}=2 \mathrm{KH}_{2} \mathrm{AsO}_{4}
$$

In the above scheme the arsenic complex undergoes oxidation-reduction processes involving the trivalent arsenic. This mechanism is similar to the chemistry of liquid phase oxidation methods, for example, LO-CAT, SulFerox (based on the iron compounds) [6]:

$$
\begin{aligned}
& 2 \mathrm{Fe}^{3+}+\mathrm{H}_{2} \mathrm{~S}=2 \mathrm{Fe}^{2+}+\mathrm{S}+2 \mathrm{H}^{+} \\
& 2 \mathrm{Fe}^{2+}+0.5 \mathrm{O}_{2}=2 \mathrm{Fe}^{3+}+2 \mathrm{OH}^{-}
\end{aligned}
$$

Eqs. (14) and (15) explain $\mathrm{pH}$ decrease under $\mathrm{H}_{2} \mathrm{~S}$ absorption and $\mathrm{pH}$ increase during solution regeneration. It should be noted that the authors [7,9] explain $\mathrm{pH}$ decrease during absorption by the neutralization reaction (1), but the Eq. (2), in their view, occurrs in the regenerator. This statement, in our opinion, is incorrect. The advantage of oxidative methods is the absence of $\mathrm{HS}^{-}$ ion coupled with dissolved $\mathrm{H}_{2} \mathrm{~S}$ in the absorber that in practice means almost complete absence of hydrogen sulfide partial pressure above the solution and a high degree of $\mathrm{H}_{2} \mathrm{~S}$ purification.

Giammarco-Vetrocoke mechanism explains why, in practice, $25 \%$ of rich solution is recycled to the top of the absorber for digestion reaction (11). This requires time for reaction and temperature increase. Naturally, the rapid flow of Eq. (1) does not require solution heating and recycling. It is well known that solution purification by thioarsenate is improved while heating.

The analytical control methods for arsenic determination and apparent activity estimation involve the pre-oxidation stage of arsenic to the pentavalent compound, and then the series of above mentioned procedures. This is also confirmed by the existence of trivalent arsenic in the working solution of thioarsenate desulfurization unit.

Control of the ORP values of rich and lean working solution during the year shows that the redox potentials of the rich solution are in the range of $(-194)-(-270) \mathrm{mV}$ $\left(E_{\mathrm{H}}=(-48)-(+28) \mathrm{mV}\right)$ and potentials of lean solution are in the range of $(-227)-(-278) \mathrm{mV}\left(\mathrm{E}_{\mathrm{H}}=(-4.9)-(-56.3) \mathrm{mV}\right)$. The solution contains several pairs of oxidized and reduced forms, but the evaluated potential transitions correspond approximately to $\mathrm{As}(\mathrm{III})-\mathrm{As}(\mathrm{V})$ transition in the diagram " $\mathrm{E}_{\mathrm{H}}-\mathrm{pH}$ " in the range of $\mathrm{pH}=7-8$.

On the other hand, when the arsenic pentasulfide precipitate is dissolved in the presence of caustic alkalis (Eq. (16)) oxy-sulphothioarsenate ion is formed, which is in equilibrium with the salt [17]. This reaction is widely used in practice for the so-called "leaching" - the increase in soda content in the washing solution for the dissolution of precipitates from scrubbers packing and increase in arsenic content in absorption solution. Thus, oxidation by air is not required for the conversion of sulphothioarsenate compound to oxy-sulphothioarsenate compounds.

$$
\mathrm{As}_{2} \mathrm{~S}_{5}+6 \mathrm{OH}^{-}=\mathrm{AsS}_{4}{ }^{3-}+\mathrm{AsO}_{3} \mathrm{~S}^{3-}+3 \mathrm{H}_{2} \mathrm{O}
$$


In [18] the equilibrium forms of the trivalent arsenic compounds in the absence of oxygen are considered when $\mathrm{Na}_{2} \mathrm{~S}, \mathrm{NaOH}, \mathrm{As}_{2} \mathrm{O}_{3}$ were dissolved in water:

$\begin{array}{rcccccc} & \mathrm{HS}^{-} & & \mathrm{HS}^{-} & & \mathrm{HS}^{-} & \\ \mathrm{AsO}_{3}{ }^{3-} & \rightarrow & \mathrm{AsO}_{2} \mathrm{~S}^{3-} & \rightarrow & \mathrm{AsOS}_{2}{ }^{3-} & \rightarrow & \mathrm{AsS}_{3}{ }^{3-} \\ & \leftarrow & \leftarrow & \leftarrow & \leftarrow \\ & \mathrm{OH}^{-} & & \mathrm{OH}^{-} & & \mathrm{OH}^{-} & \end{array}$

Thus, the conversion of oxy-sulphothioarsenate compounds with different S/As ratios explains only the absorption step, the regeneration step of this mechanism and excessive oxidation of arsenic with formation of "oxygen" salt require an altered chemism of thioarsenate desulfurization process.

\section{Conclusions}

Measurement of the redox potential is useful as the less time-consuming analysis for influence estimation of working solution contaminants. This will allow to determine quickly the most interfering impurities in the solution. ORP measurement is less laboriuos analysis than the traditional method of apparent activity estimation on the basis of determination of "total", "oxygenated" and "residual" arsenic.

The production data show that the traditional method of thiosulfate concentration determination indirectly reflects $\mathrm{As}^{3+}$ content that affects the process operation. A conventional Gollmar mechanism does not involve the trivalent arsenic compounds.

The mechanism proposed by V. Nizhegorodtsev [9], is based on the redox processes of arsenic compounds. However, it has several limitations, for instance the presence of $\mathrm{HS}^{-}$(that must be coupled with undissociated $\mathrm{H}_{2} \mathrm{~S}$ under $\left.\mathrm{pH}=7.4-7.6\right)$ in the absorbent does not explain the absence of hydrogen sulfide partial pressure over the rich solution and the low content of $\mathrm{H}_{2} \mathrm{~S}$ in the purified gas. From this point it is hard to explain the necessity of $25 \%$ rich solution recycle at the absorption stage and insufficient regeneration only by impurities influence.

Giammarco-Vetrocoke mechanism can be considered as the closest to the explanation of the process, despite the statement [6] that the process fundamentally differs from the thioarsenate one.

For the full control of the process a new interpretation of the basic redox reactions chemism based on the Giammarco-Vetrocoke reactions is required. It is also necessary to establish the solubility of the compounds of the main forms of arsenic, and modernize the analytical methods for determination $\mathrm{S}_{2} \mathrm{O}_{3}{ }^{2-}, \mathrm{As}^{5+}$ and $\mathrm{As}^{3+}$ concentrations.

\section{References}

[1] Golovko M., Drozdnik I., Miroshnichenko D. and Kaftan Y.: Koks i Khimiya, 2012, 55, 204.

[2] Golovko M., Drozdnik I., Miroshnichenko D. and Kaftan Y.: Koks i Khimiya, 2011, 54, 139.

[3] Miroshnichenko D., Desna N. and Ulanovskiy M.: Koks i Khimiya, 2014, 57, 276.

[4] Kovalev E.: Ulavlivanie i Pererabotka Khimicheskih Produktov Koksovaniya, Tom 3. Izd. dom "INZHEK", Kharkov 2009.

[5] Yavorsky V.: Tehnologiya Sirky i Sulfatnoi Kisloty. Lvivska politehnika, Lviv 2010.

[6] Kohl N.: Gas Purification. GulfPubl. Comp., Houston 1997.

[7] Sokolik L., Spirina T., Vail E. et al.: Koks i Khimiya, 1989, 4, 25.

[8] Grumberg L. and Shchetinina M.: Voprosy Techn. Ulavlivaniya i Pererabotki Produktov Koksovaniya, 1974, 2, 45.

[9] Nizhegorodtsev V., Ulianov B. and Doshlov O.: Trudy Inst. Problem Upravleniya, Seriya Khim., 1973, 220.

[10] Sliuzar A.: Lviv Polytechnic National University Institutional Repository, 2011, http://ena.lp.edu.ua.

[11] Sliuzar A., Kalymon Ya., Zozulia G. and Kochanska N.: Visnyk Nats. Univ. "Lvivska Politechnika”, 2005, 536, 186.

[12] Bannikov L., Kovalev E. and Toshchinsky V.: Uglekhim. Zh., 2007, 6, 59.

[13] Ghurye G. and Clifford D.: Laboratory Study on the Oxidation Arsenic(III) to Arsenic(IV)/US Environmental protection Agency EPA/600/R-01/021, 2001, 104.

[14] Golyand S.: Soobshchenie Hiprokoksa, 1956, 17, 58.

[15] Zymin A. and Litvin P.: Uglechim. Zh., 2005, 5-6, 36.

[16] Walsh K., Salaun P. and van den Berg C.: Analytica Chim. Acta, 2012, 710, 50.

[17] Nemorduk A.: Analiticheskaya Khimiya Myshyaka. Nedra, Moskva 1976.

[18] Wen Li: B. Sc., (Material Engineering), Hebey University of Technology, China 2006.

\section{ІНТЕРПРЕТАЦІЯ ВПЛИВУ СОЛЕЙ НА РЕГЕНЕРАЦЮЮ НАСИЧЕНОГО МИШ'ЯКОВО-СОДОВОГО РОЗЧИНУ ЗА ДОПОМОГОЮ ВИМІРЮВАННЯ ОКИСНО-ВІДНОВНОГО ПОТЕНЦАЛУ}

Анотація. Досліджено вплив різних забруднювачів у прочесі очшщення коксового газу від сірководню миш'яковосодовим розчином внаслідок вимірювання окисно-відновного потениіалу (ОВП). Вимірювання ОВП є простим і показовим методом визначення активності розчину. Розглянуто вплив тіосульфату на активність поглинального розчину на основі розгляду перетворень миш'яку $\left(A s^{3+} / A s^{5+}\right)$.

Ключові слова: мии'яково-содовий метод, активність, забруднюючий ефект. 